\title{
ANALISIS FAKTOR PENYEBAB DAN DAMPAKNYA BANJIR DIKALIMANTAN SELATAN TAHUN 2021
}

\section{Helpina}

2010128120010@mhs.ulm.ac.id

Program Studi Pendidikan IPS

Fakultas Keguruan dan Ilmu Pendidikan

Universitas Lambung Mangkurat

Banjarmasin

\begin{abstract}
Banjir yang terjadi dikalimantan selatan sangat merugikan sekali bagi setiap warganya banyak sekali kerugian yang terjadi baik ekonomi, material maupun aktivitas sosial yang terhenti. terjadinya banjir dikarenakan curah hujan yang tinggi, dan penurunan luas hutan yang membuat berkurangnya daerah resapan air. Maka dari itu dibutuhkan kajian dalam mengidentifikasi factor-faktor penyebab banjir yang terjadi dikalimantan selatan Agar setiap warganya mengetahui akibat dari perbuatan yang dilakukan agar tidak tidak terjadi lagi banjir. Dalam arikel ini berisikan penelitian mengenai penyebab banjir yang terjadi dikalimantan selatan. Metode penelitian yang digunakan adalah metode penelitian kualitatif yitu mendeskripsikan dan menganalisis diberbagai jurnal dan artikel. Dari hasil penelitian disebutkan bahwa factor penyebab banjir di Kalimantan selatan adalah, tingginya curah hujan, dan kurangnya daerah hutan yang membuat kurangnya juga resapan air.
\end{abstract}

\section{Kata kunci}

Banjir, Kalimantan selatan , curah hujan, hutan

\section{Pendahuluan}

Keadaan debit air sungai yang melebihi debit aliran normal disebut banjir dalam hidrologi, yang diakibatkan oleh hujan yang turun diatas permukaan tanah dan saluran sungai. Jatuhnya air diatas permukaan tanah akan mengalami intersepsi atau langsung gugur diatas tanah. Setelah itu akan terbentuk lapisan tipis air diatas permukaan tanah yamg dikela dengan sunface detension. Setelah itu jadilah linier. Karena ketebalannya bertambah maka kecepatan aliran juga bertambah dan turbulensinya bertambah juga hal ini disebut dengan pverland flow.dan akan membuat saluran sungai memperbrsar limpasan.( Puspitarini, R. C. (2021)). 
Banjir juga merupakan suatu kejadian alam yang terjadi akibat tingginya curah hujan yang mengakibatkan meluapnya air dibeberapa daerah dikalimantan selatan yaitu kota Banjarmasin, kabupaten huku sungai, kabupaten balangan, banjarbaru, kabupaten tapin, kabupaten hlu sungai utara,kabupaten tanah laut dan kabupaten banjar yang terjadi pada bulan januari tahun 2021 yang ketinggian airnya dari 30cm sampai 3 meter diberbagai wilayah. (Kusumastuti, D. I. (2011). Banjir yang terjadi disebabkan oleh intensitas curah hujan yang tinggi yang membuat luapan air. Tidak hanya itu banjir bisa juga di sebabkan degradasi lingkungan akibat dari banyaknya lubang pertambangan yang tidak melakukan reklamasi. Pada kondisi ini banyak sekali menimbulkan kerugian bagi masyarakat sekitar. Dengan kurangnya hutan didaerah tersebut mengakibatkan air yang datang tidak bisa diresap dan mengakibatkan banjir.( Puspitarini, R. C. (2021)

Daerah Kalimantan selatan merupakan salah satu wilayah yang rawan banjir dikarenakan daerah tersebut termasuk daerah aliran sungai yang memiliki karakteristik akan meluap apabila turun hujan yang deras berhari-hari dan kurangnya hutan untuk daerah resapan air. kurangnya daerah resapan air terjadi karena pertumbuhan pembanguann. Kondisi tersebut merupakan faktor terjadinya banjir. Dampak dari banjir diwilayah Kalimantan selatan adalah jalanan yang terendam menganggu aktiviatas ekonomi masyarakat dan jembatan pengubung antar daerah yang putus juga membuat setiap aktifitas masyakarat terganggu.( Puspitarini, R. C. $(2021)$

Apabila kondisi tersebut terus terjadi dikalimantan selatan dapat menyebabkan dampak yang besar bagi masyarakatnya. Maka dari itu tujuan penulisan artikel ini adalah agar bisa diketahui faktor penyebab dari banjir dikalimantan selatan agar setiap masyarakatnya tahu dan bisa menjaganya.

\section{Metode}

Dalam penelitian ini menggunakan metode pengumpulan data dengan Teknik kualitatif yaitu menganalisis dan mendeskripsikan di berbagai jurnal maupun artikel yang bersangkutan untuk mengetahui faktor penyebab terjadinya banjir di Kalimantan selatan dan dampaknya bagi masyarakat sekitarnya. 


\section{Pembahasan}

Dari hasil analisis di jurnal terapat 2 faktor peyebab banjir dikalimantan selatan yaitu faktor alam dan non alam yang ada yaitu, curah hujan yag tinggi dapat membuat air sungai juga meluap dan kurangnya daerah resapan air atau hutan yang gundul membuat air yang turun tidak ada yang diresap( Puspitarini, R. C. (2021)..wilayah Banjarmasin yang dikelilingi sungaisungai yang besar sangat benyak sekali manfaatnya contohnya sebagai pelayaran (Subiyakto, 2005).

Sungai yang berada dikalimantan selatan juga digunalan sebagai pengubung beberapa daerah contonya daerah Kalimantan selatan dan Kalimantan tengah. Namun adanya sungai juga dapat berdampak negative bagi masyarakat yaitu sungai bisa meluap dan dapat membuat banjir. . Sungai yang ada dikalimantan termasuk sungai yang besar yang berada di dunia. Disungai ini ada pengaruh kekuatan hidromatika terhadap lingkungan perairan lainnya (Mutiani, Putra, Abbas, Subiyakto, \& Oktaviani, 2020)

Sungai ini banyak sekali memiliki manfaat namun juga banyak juga dapat mengakibatkan kerugian. Manfaat dari sungai adalah tidak hnya sebagai jalur transfortasi namun juga berfungsi sebagai tempat berlangsungnya kegiatan ekonomi, aktifitas masyrakat kadang juga di lakukan disungai seperti mandi,dan mencuci,tidak hnya itu sengai dalam asfek siosial juga berfungsi sebagai tempat berlangsungnya inteksi sosial masyarakat. (Jumriani 2020)

Salah satu isu nasional dalam beberapa tahun terakhir ini adalah Daerah Aliran Sungai (DAS) atau cekungan sungai yang menyebabkan banjir. Tidak hanya itu penyimpangan tata guna lahan juga merupakan faktor penyebab banjir yang ada dikalimantan selatan (Puspitarini, R. C. (2021). Bencana alam yang yang sering terjadi dikalimantan selatan adalah banjir karena Kalimantan selatan memiliki dataran rendah. Banjir dapat disebabkan oleh beberapa faktor salah satunyayaitu tingginya curah hujan yang turun . tingginya curah hujan yang membuat air sungai meluap dan membuat banjir didaerahnya tersebut.( Kadir, S., Sirang, K., \& Badaruddin, B. (2016)

Ketika hujan yang turun melebihi kapasitas maka sungai tidak mampu mengatuskan limpasan permukaan sungai dan dapat menggenangi daerah sekitarnya.Peningkatan intensitas curah hujan secara dinamis dan signifikan yang terjadi pada umumnya disebabkan oleh 
peningkatan gejala dari pemanasan global berupa kenaikan suhu permukaan bumi yang disebabkan oleh aktivitas yang terjadi di permukaan. Tidak hanya itu Banjir juga bisa diakibatkan oleh perubahan fungsi lahan pada Kawasan hutan lindung yang dapat mengurangi fungsi resapan air. Salah satu alih fungsi lahan yang sering terjadi di daerah Kalimantan adalah fungsi hutan yang serusnya jadi daerah resapan air menjadi perkebunan sawit, pembangunan pemukiman dan lain-lain.( Puspitarini, R. C. (2021)

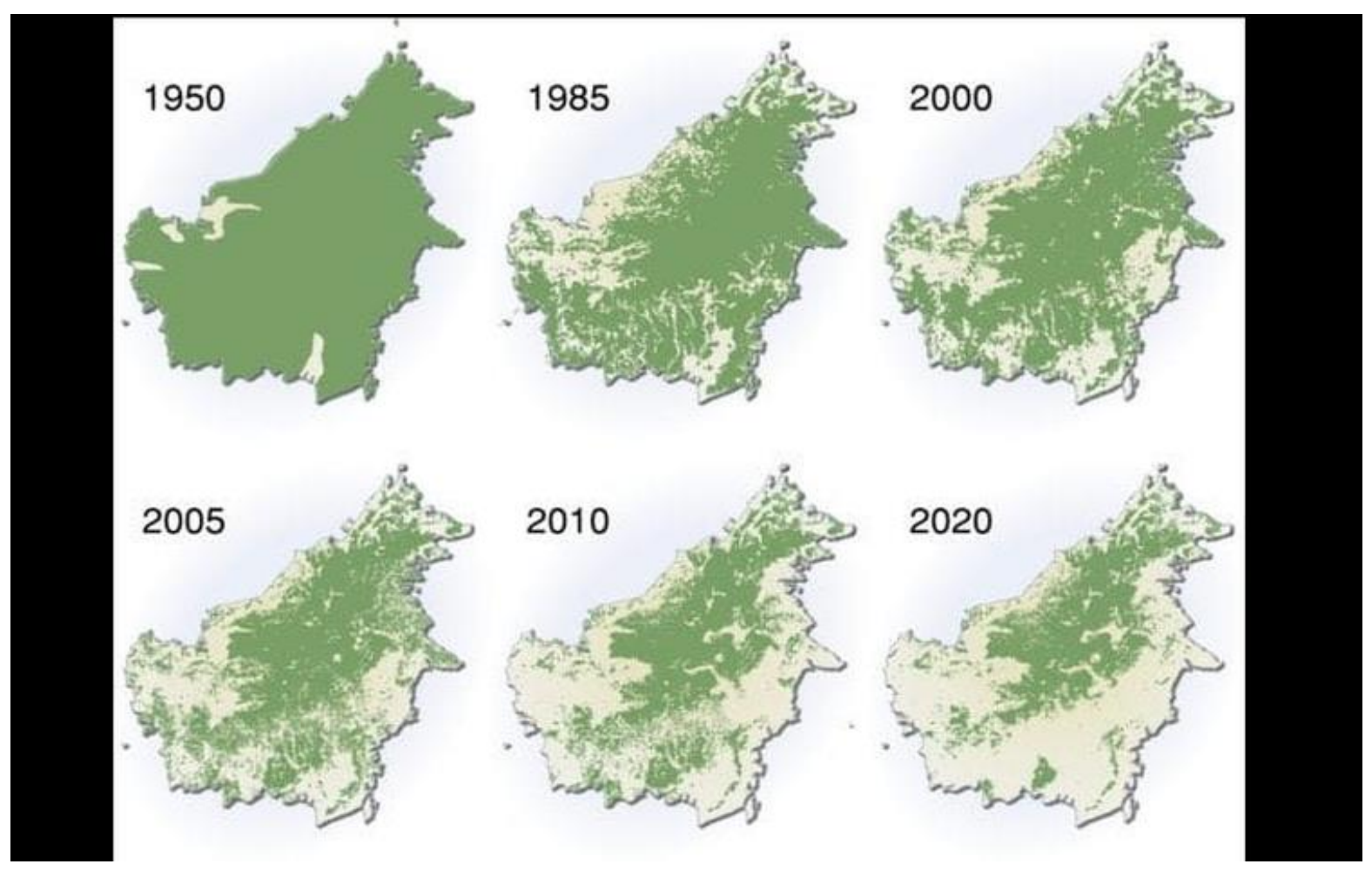

Sources:Radday, M. 2007 'Borneo Maps'

Kawasan yang ditandai dengan warna hijau adalah ilustrasi pencitraan yang mana hutan di Borneo masih terjaga. Sedangkan ilustrasi dengan warna putih adalah alih fungsi hutan menjadi beragam bentuk yang bernilai ekonomimulai dari perkebunan sawit, penambangan, konsumsi kayu, dan lainnya. Perubahan fungsi lahan juga berpengaruh pada peningkatan masuknyamaterial erosi ke dalam saluran, sungai dan tampungan air. Perubahan fungsi lahan juga berpengaruh pada peningkatan masuknya material erosi ke dalam saluran, sungai dan tampungan air. .( Puspitarini, R. C. (2021)

Akibat dari pengaruh kepadatan bangunan sangat berdampak sekali bangi masyrakat dan lingkungannya. Karena padatnya bangunan akan mengurangi luasnya sungai dan saluran drainase. Yang dapat menimbulkan genangan air yang akan menjadi banjir dalam jangka waktu yang lama dan besar. Daerah Kalimantan selatan saat ini pertumbuhan penduduk meningkat yang dapat mengakibatkan kepadatan bangunan bertambah juga. (Kumalawati, R., Angriani, F., \& Rahmani, D. R. (2018). 
Perubahan fungsi lahan yang terjadi dikalimantan selatan seperti lahan hutan yang rimbun dijadikan pemukiman. Seharusnya daerah tersebut menjadi Kawasan resapan air.dengan kurangnya daerah resapan iar dapat ,membuat datangnya banjir di daerah Kalimantan selatan.( Rosyidie, A. (2013).

Baniir yang terjadi dikalimantan selatan berdampak negative bagi masyarakatnya dampaknya bersifat langsung maupun tidak langsung. Tidak hanya itu banjir juga mengakibatkan banyaknya rumah warga yang rusak, jalanan yang terputus, jembatan terputus,dan semua budidaya ikan warga sekitar hilang terbawa arus. (Deasy, A. (2017)

Tabel Daerah yang terdampaak banjir dikalimantan selatan yaitu sebagai berikut:

\begin{tabular}{|l|l|l|l|}
\hline No & Kabupaten/kota & Rumah terdampak & Jiwa terdampak \\
\hline 1. & Kabupaten Tapin & 582 rumah & 382 jiwa \\
\hline 2. & Kabupaten Banjar & 6.670 rumah & 11.269 jiwa \\
\hline 3. & Kota Banjar & 2.156 rumah & 3.690 jiwa \\
\hline 4. & Tanah Laut & 8.506 rumah & 13.062 jiwa \\
\hline 5. & Kabupaten Balangan & 1.154 rumah & 17.501 jiwa \\
\hline 6. & Kabupaten Tabalong & 407 rumah & 770 jiwa \\
\hline 7. & Kabupaten Hulu Sungai Tengah & 11.200 rumah & 64.400 jiwa \\
\hline 8. & Kabupaten Hulu Sungai Selatan & 387 rumah & 387 rumah \\
\hline 9. & Kabupaten Batola & 517 rumah & 28.400 jiwa \\
\hline
\end{tabular}

Kepala Pusat Data, Informasi dan Komunikasi Kebencanaan BNP

Untuk menangulangi banjir maka harus dilakukan berbagai upaya baik dari masyarakat maupun pemerintah. Solusi mengendalikan banjir secara ekologi yaitu dengan membangun ekositem hutan dan ekosistem sungai yang terencana.( Erlia, D., Kumalawati, R., \& Aristin, N. F. (2017)

Pencapaian Sasaran Nasional Penanggulangan Bencana dilaksanakan dengan menerapkan Kebijakan Nasional penanggulangan bencana yang terdiri dari, (1)Penguatan dan Harmonisasi Sistem, Regulasi serta Tata Kelola PB yang efektif dan efisien, dengan strategi Penguatan dan harmonisasi peraturan perundang-undangan penanggulangan bencana, Penguatan tata kelola penanggulangan bencana yang semakin profesional, transparan, dan akuntabel, Peningkatan sinergi antar kementerian/lembaga dan pemangku kepentingan dalam penanggulangan bencana, dengan strategi. (2)Penerapan riset inovasi dan teknologi 
kebencanaan melalui integrasi kolaboratif multi pihak, Penguatan investasi pengelolaan risiko bencana sesuai dengan proyeksi peningkatan risiko bencana, dengan strategi, (3)Peningkatan Sarana Prasarana Mitigasi dan Pengurangan Risiko Bencana, Penguatan Sistem Kesiapsiagaan Bencana, Pemberdayaan masyarakat dalam penanggulangan bencana dengan pendekatan rekayasa sosial yang kolaboratif (collaborative social engineering), (4)Peningkatan perlindungan terhadap kerentanan lingkungan di daerah rawan bencana. Peningkatan kapasitas dan kapabilitas penanganan kedaruratan bencana yang cepat dan andal, dengan strategi Penguatan Sistem dan Operasionalisasi Penanganan Darurat Bencana, Percepatan pemulihan daerah dan masyarakat terdampak bencana untuk membangun kehidupan yang lebih baik, dengan strategi Percepatan Penyelenggaraan Rehabilitasi dan Rekonstruksi di daerah terdampak bencana.( Erlia, D., Kumalawati, R., \& Aristin, N. F. (2017)

Sistem penanggulangan banjir juga dapat digunakan dengan memanfaatkan Sistem Informasi Geografi (SIG) dan ketersediaan data digital untuk kawasan regional maupun global. Data digital dapat dihasilkandari scanningpetawilayah, foto udara atau citra yang dihasilkan satelit, profil saluran drainase dan bangunan-bangunan drainase yang diperlukan sebelum melakukan perencanaan ulang drainase. Hal inibermanfaat sebagai referensi yang dapat memudahkan proses pengambilan keputusan, agar pengambilan keputusan benar-benar dibuat berdasarkan fakta eksisting yang ada. Bukan dibuat berdasarkan untuk memuaskan keinginan salah satu pemangku kepentingan tertentu.( Kurnain, A., \& Soendjoto, M. A. (2007)

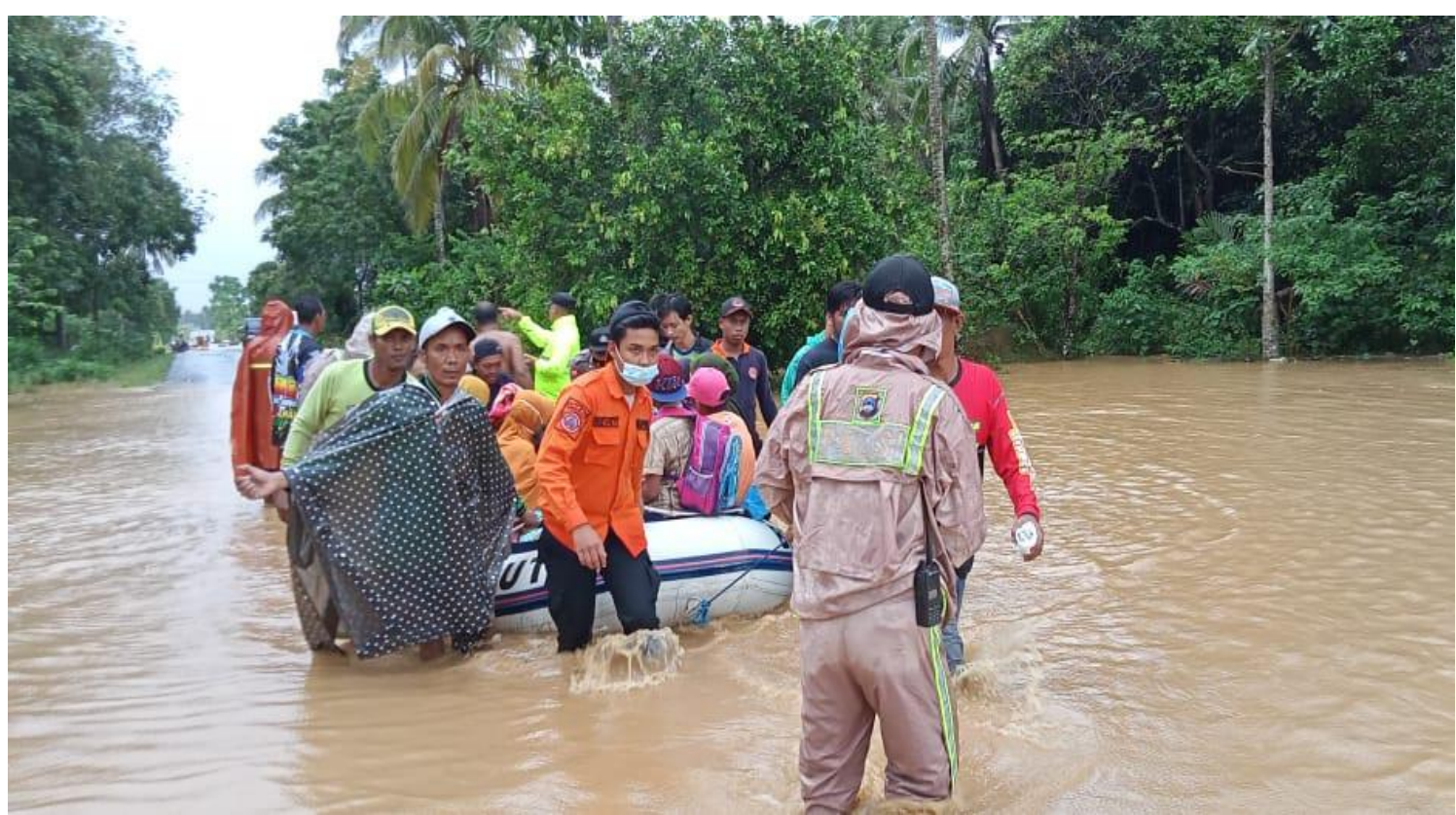

Foto : Banjir di Kabupaten Tanah Laut 


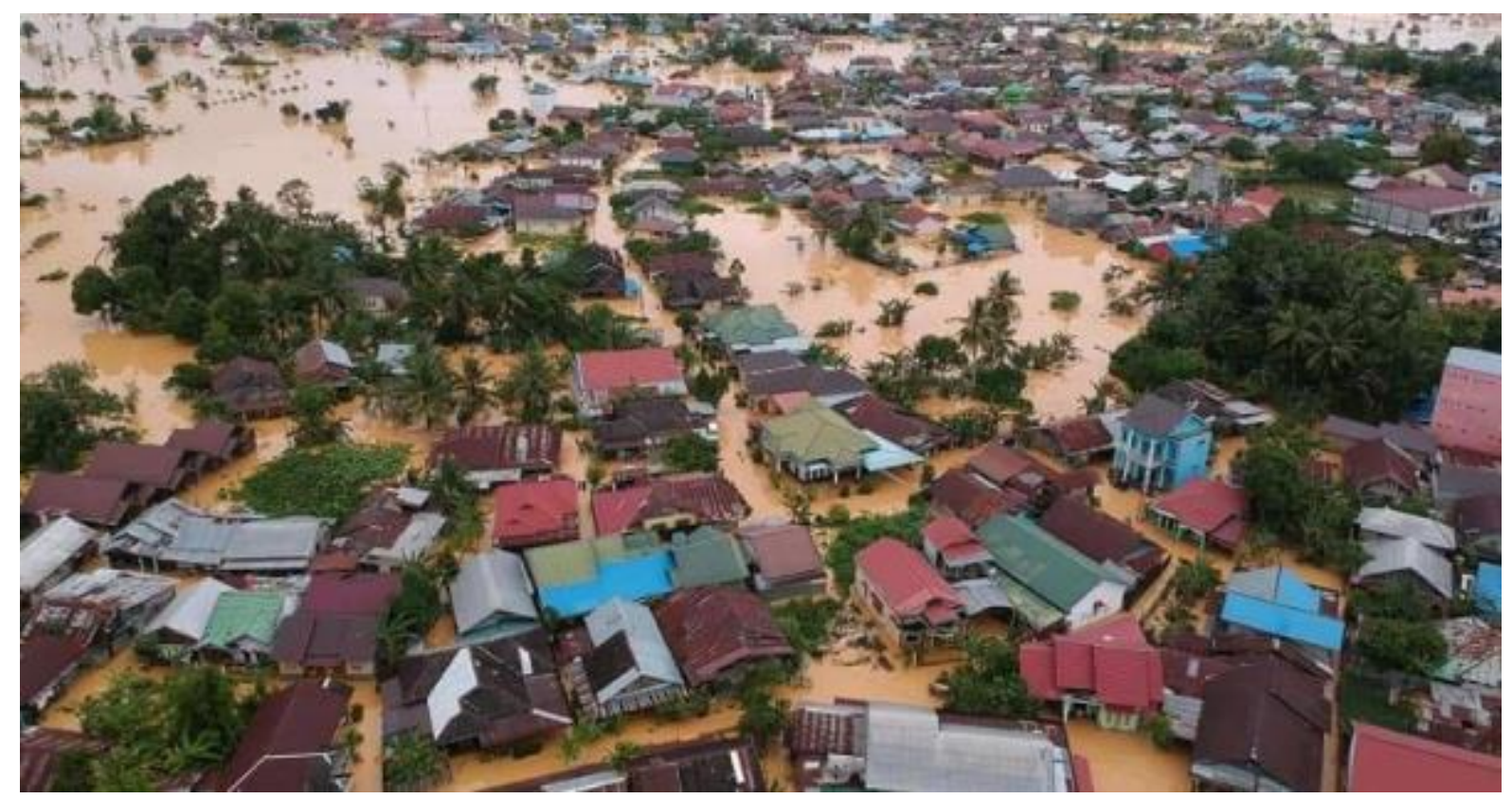

instagram.com/dinsosp2kbp3a.hst

\section{Simpulan}

Berdasarkan hasil Analisa dan pembahasan yang telah dilakukan maka dapat disimpulkan bahwa faktor penyebab terbesar banjir dikalimantan selatan adalah curah hujan yang tinggi membuat meluapnya air sungai, dan kurangnya daerah resapan air yang disebabkan banyaknya pembangunan pemukiman dan degradasi lingkungan.

Akibat dari pengaruh kepadatan bangunan sangat berdampak sekali bangi masyrakat dan lingkungannya. Karena padatnya bangunan akan mengurangi luasnya sungai dan saluran drainase yang dapat menimbulkan genangan air yang akan menjadi banjir dalam jangka waktu yang lama dan besar. Daerah Kalimantan selatan saat ini pertumbuhan penduduk meningkat yang dapat mengakibatkan kepadatan bangunan bertambah juga.

Perubahan fungsi lahan yang terjadi dikalimantan selatan seperti lahan hutan yang rimbun dijadikan pemukiman. Seharusnya daerah tersebut menjadi Kawasan resapan air.dengan kurangnya daerah resapan iar dapat, membuat datangnya banjir di daerah Kalimantan selatan. 


\section{Referensi}

Adlyatma, R. (2018). Studi Normalisasi Sungai Kemuning Dalam Penanggulangan Banjir Di Kota Banjarbaru Kalimantan Selatan. Jurnal Rekayasa Sipil, 1(1).

Deasy, A. (2017). Dampak Bencana Banjir Terhadap Kondisi Sosial Ekonomi masyarakat di Kecamatan Batu Benawa Kabupaten Hulu Sungai Tengah, Kalimantan Selatan. JPG (Jurnal Pendidikan Geografi), 4(4), 42-52.

Erlia, D., Kumalawati, R., \& Aristin, N. F. (2017). Analisis kesiapsiagaan masyarakat dan pemerintah menghadapi bencana banjir di Kecamatan Martapura Barat Kabupaten Banjar. JPG (Jurnal Pendidikan Geografi), 4(3).

Rosyidie, A. (2013). Banjir: fakta dan dampaknya, serta pengaruh dari perubahan guna lahan. Jurnal Perencanaan Wilayah dan Kota, 24(3), 241-249.

Puspitarini, R. C. (2021). Perspektif Melihat Banjir Kalimantan Selatan Tahun 2021. Jurnal Sosial Politik Integratif, 1(1), 1-14.

Kusumastuti, D. I. (2011). Analisis Dampak Tanggul terhadap Elevasi Banjir Sungai Nagara Kalimantan Selatan. Rekayasa: Jurnal Ilmiah Fakultas Teknik Universitas Lampung, 15(3), 183-192.

Kumalawati, R., Angriani, F., \& Rahmani, D. R. (2018). KRITERIA RUANG TERBAIK KOMPLEK PERMUKIMAN BERDASARKAN PEMETAAN RISIKO BENCANA BANJIR DI KABUPATEN HULU SUNGAI TENGAH KALIMANTAN SELATAN. Jukung (Jurnal Teknik Lingkungan), 4(1).

Kurnain, A., \& Soendjoto, M. A. (2007). Kerusakan dan bencana lingkungan terrestrial di Kalimantan Selatan serta pencegahan dan penanggulangannya. Prosiding Temu Ilmiah Terbuka UNLAM" Banjir, Kebakaran, dan Kekeringan: Pencegahan dan Penanganannya", 5-12.

Kadir, S., Sirang, K., \& Badaruddin, B. (2016). Pengendalian Banjir Berdasarkan Kelas Kemampuan Lahan Di Sub DAS Martapura Kabupaten Banjar Kalimantan Selatan. Jurnal Hutan Tropis, 4(3), 254-264.

Subiyakto, B., Abbas, E. W., Arisanty, D., Mutiani, M., \& Akmal, H. (2020). Sungai dan Kehidupan Masyarakat Banjar: Penguatan Lokalitas dalam Wacana Pendidikan IPS yang Responsif. 